\title{
Electronic Tongue System to Evaluate Flavor of Soybean (Glycine Max (L.) Merrill) Genotypes
}

\author{
Sandra Maria Zoldan ${ }^{1}$, Guilherme de Souza Braga ${ }^{2}$, Fernando Josepetti Fonseca ${ }^{2}$ and \\ Mercedes Concórdia Carrão-Panizzi ${ }^{1 *}$ \\ ${ }^{I}$ Embrapa, Centro Nacional de Pesquisa de Trigo; Passo Fundo - RS - Brasil. ${ }^{2}$ Departamento de Engenharia de \\ Sistemas Eletrônicos; Escola Politécnica; Universidade de São Paulo; São Paulo - SP - Brasil.
}

\begin{abstract}
An electronic tongue system was tested as a fast and efficient analytical tool for flavor evaluation of soybean genotypes. Grain samples of 25 soybean lines were analyzed using $0.25 \mathrm{~g}$ of milled samples added to $100 \mathrm{~mL}$ of distilled water and mixing for one minute on a magnetic stirrer. An aliquot $(50 \mathrm{~mL})$ from the filtered liquid was used for the analysis on a pre-fixed frequency of $1 \mathrm{kHz}$ and alternate tension of $50 \mathrm{mV}$. Two analyses were conducted in a complete randomized design with three replicates. Electrical response (capacitance) of eight polymeric chemical sensors used to analyze the soybean lines were submitted to Principal Component Analysis (PCA). In the spatial distribution of the PCA graphic, the lines close to each other were similar, while the distant ones showed different characteristics. The electronic tongue system was efficient in discriminating flavor of soybean lines.
\end{abstract}

Key words: Electronic tongue system, chemical sensors, special soybean grains, beany flavor, vegetable types

\section{INTRODUCTION}

Flavor and other special chemical and physical characteristics are the main objectives to breed soybean for human consumption (Carrão-Panizzi 2000). To improve soybean flavor, two approaches are considered at the breeding program of Embrapa: elimination of the lipoxygenase isoenzymes (L1L2L3), responsible for the development of the beany flavor in soybean products (Furuta et al. 1996); and introduction of the good flavor of soybean vegetable types ("edamame" or fresh green soybeans), which is due to higher concentrations of starch, sucrose, fructose, glutamic acid and alanine (Masuda 1991). The breeding program released the null lipoxygenase soybean cultivars BRS 213 and BRS 257 that could prevent the formation of hexanal, improving the flavor of the soybean products (Carrão-Panizzi et al. 2009; Silva et al. 2009), and cultivar BRS 267 (a vegetable type) that presented large seed size, better flavor and could be consumed as "edamame" (Carrão-Panizzi et al. 2001; Silva et al. 2009).

Therefore, to release the soybean cultivars for human consumption, flavor characteristics should be evaluated by sensorial analysis (Silva et al. 2009). In general, these methodologies are costly, time consuming, and demand training of the tasters (Meilgaard et al. 1999; Stone and Sidel 2004). In breeding programs, when a large number of lines and small amount of samples (seeds) are available, a rapid and efficient methodology is needed to analyze the flavor. In previous studies, it was reported that the electronic tongue (ET) system was efficient in detecting differences in the flavor (Silva et al. 2012). It was

\footnotetext{
*Author for correspondence: mercedes.panizzi@embrapa.br
} 
able to detect different soybean flavor as beany, umami, sweet, bitter and astringent. Data of the electronic tongue system was also correlated with results from the sensorial and chemical analyses (Silva et al. 2012).

The electronic tongue system can detect the basic tastes in very small amounts, much lower than the human threshold perception (Mattoso et al. 2002). Several studies have been made on the efficiency of electronic tongue to evaluate the flavor of several products and confirm the results by correlating them with those obtained from sensorial analyzes that used a panel of trained tasters (Legin et al. 2002; Andersson 2003; Kataoka et al. 2004; Dyminski et al. 2006). With the objective to validate the use of electronic tongue to determine the flavor of breeding lines, two experiments were conducted: 1) three methodologies of flavor extraction were evaluated in order to speed-up the flavor analyzes of a large number of samples by the ET, and 2) lines from the breeding program were analyzed to verify the efficiency of the chemical sensors in separating flavor differences among the lines.

\section{MATERIALS AND METHODS}

\section{Experiment 1 - Flavor extraction}

For the study of flavor extraction, milled grains of three soybean cultivars, with different flavor characteristics: the normal cultivar BRS 232 (bad flavor), the null lipoxygenase cultivar BRS 257 (good flavor) and the vegetable type cultivar BRS 267 (superior flavor) were used. The grains were milled in coffee grinder (Cadence) and $0.25 \mathrm{~g}$ samples were added to $100 \mathrm{~mL}$ of distilled water. The mixture was agitated on magnetic stirrer (LSLogen agitator) for 01,10 and $20 \mathrm{~min}$ (T1, T10 and T20, respectively). Then the suspensions were filtered in coffee paper filter and $50 \mathrm{~mL}$ of the filtrate was submitted to the electronic tongue system analyzes. Before the analyses by the ET, samples temperature was stabilized to $24^{\circ} \mathrm{C}$ in thermostatic bath (Quimis). The $\mathrm{pH}$ of the samples was also measured ( $\mathrm{pH}$ meter Analion-PM 608). All the samples were prepared in three replications.

\section{Electronic tongue analyzes}

Samples were analyzed in an electronic tongue system with 08 non-specific polymeric chemical sensors, which were determined in previous works (Paterno and Mattoso 2001; Paterno et al. 2001). Each sensor was composed by a gold interdigited microelectrode (50 pairs of digits) coated with a polymeric film by using the layer-by-layer (LbL) technique throughout the electrostatic attraction (Decher 1997). Film deposition was made by an automated system (robot Haubenteuer, da VCompany do Brasil) as described by Braga et al. (2008) that performed the deposition by immersing the microelectrodes alternately into the polycation and polyanion solutions for $3 \mathrm{~min}$. Between each adsorbed layer, the microelectrode was moved into a diluted $\mathrm{HCl}$ solution under stirring to clean the excess of polyelectrolytes. After that, they were exposed to air (room temperature, $25^{\circ} \mathrm{C}$ ) to dry for $5 \mathrm{~min}$ and continuing deposition of the next layer. Detailed description of the film deposition, polyelectrolyte solutions and sensors coatings were as described by Gregorut (2010).

The electrical impedance response of the sensors was obtained by using an impedance meter type LCR (HP LCR Meter model 4263A) interfacing with a computer through the plaque GPIB. Measurements and data acquisition were performed by the computer with the aid of a virtual instrument created in LabView, developed at Embrapa Agricultural Instrumentation.

The soy samples were analyzed at random sequence, while immersed in a thermostatic bath set at $24^{\circ} \mathrm{C}$. Measurements were also made in prefixed frequencies at $1 \mathrm{kHz}$ and alternate tension of $50 \mathrm{mV}$ and were started after conditioning the sensors into the soy samples for $1 \mathrm{~min}$. This was the minimum time for the sensors signals reach the steady-state condition.

\section{Statistical analyzes randomized block design}

For this first experiment, a completely randomized design was used, with three replications in a factorial arrangement $2^{3}$ of three flavor extraction time (T1, T10 andT20), and three soybean cultivars with flavor differences (BRS 232, BRS 257 and BRS 267). Results were submitted to the Principal Component Analyzis (PCA) (Borato 2002).

\section{Experiment 2 - Flavor analysis of the breeding lines}

Twenty three soybean lines from the breeding program of Embrapa and two soybean cultivars, sowed in Passo Fundo, Rio Grande do Sul State at 
Embrapa Wheat, during 2010/2011 growing season, were selected for flavor evaluation. Table 1 shows these lines are according to their special characteristics, which are high protein content, reduced trypsin inhibitor, reduced phytate content and better flavor that can be due to the absence of enzyme lipoxygenases or to the special flavor of the soybean vegetable types.

The samples of dried soybean grains of the 25 genotypes with different flavor characteristics (Table 1) were milled and extracted similar to that described above.

Table 1 - Special characteristics of soybean breeding lines evaluated by electronic sensors.

\begin{tabular}{clccl}
\hline Number & Line & Hilum color & Seed coat (color) & Special attribute \\
\hline 3 & BR09-05344 & Brown & Yellow & Null lipoxygenase \\
4 & BR09-08365 & Light brown & Yellow & High protein content \\
7 & BRM08-50410 & Light brown & Yellow/Green & Reduced trypsin inhibitor \\
8 & BRM08-50636 & Yellow & Yellow & Reduced phytate \\
10 & BRM08-50643 & Black & Yellow & High protein and flavor \\
11 & BRM08-50680 & Brown & Yellow & High protein and flavor \\
12 & BRM08-50939 & Brown & Yellow & High protein and flavor \\
13 & BRM08-50964 & Light brown & Yellow & Large seed size \\
15 & BRM08-51043 & Light brown & Yellow & Reduced trypsin inhibitor \\
16 & BRM08-51082 & Light brown & Yellow & Large seed size \\
17 & BRM08-51344 & Light brown & Yellow & Reduced trypsin inhibitor \\
18 & BRM08-51412 & Light brown & Yellow & Superior flavor \\
19 & BRM08-51830 & Black & Yellow & Superior flavor \\
20 & BRM09-50957am & Yellow & Yellow & Superior flavor \\
$021 \mathrm{~A}$ & BRM09-50957me & Brown & Dark Brown & Superior flavor \\
$021 \mathrm{~B}$ & BRM09-50957mc & Brown & Light brown & Superior flavor \\
22 & BRM09-50682pt & Black & Black & Superior flavor \\
23 & BRM09-50901pt & Black & Black & Superior flavor \\
$024 \mathrm{~A}$ & BRM09-50995am & Black & Yellow & Superior flavor \\
$024 \mathrm{~B}$ & BRM09-50995pt & Black & Black & Superior flavor \\
25 & BRM09-50994pt & Black & Black & Superior flavor \\
26 & BRM09-51075pt & Black & Black & Superior flavor \\
27 & BRM08-51622 & Yellow & Yellow & Superior flavor \\
29 & BRS 267 & Yellow & Yellow & Superior flavor \\
30 & BRS 213 & Yellow & Yellow & Null lipoxygenase \\
\hline
\end{tabular}

\section{RESULTS AND DISCUSSION}

\section{Experiment 1 - Flavor extraction}

Easy and rapid sample preparation for flavor extraction is needed to allow analyzes of a large number of samples. Otherwise, flavor analyzes by the electronic tongue would not be useful and could also be time consuming similar to sensorial analysis. The tested times of T1, T10 and T20 for sample preparation allowed the detection of flavor differences among the tested cultivars. The PCA graphic (Fig. 1) for T1 treatment showed all the evaluated cultivars in separate position, which was well distinguished for BRS 232, the grain type soybean with bad flavor, and for BRS 267, the vegetable type with better flavor. Cultivar BRS 257 was not well positioned and one of the replications was far from the others, which could not have been detected. Cultivars BRS 257 and BRS 267, both released as special soybean cultivars, showed better flavor characteristic that was due to different characters, such as absence of the lipoxygenases and different sugar profile, respectively. The better flavor of cultivar BRS 267 was due to the Japanese vegetable type genotype that was in its genealogy. The flavor of vegetable types was different from the one observed for null lipoxygenase character.

Therefore, these good flavor differences put those two cultivars (BRS 267 and BRS 257) in a separate position, although at the same side of the graphic. For 10 min (T10) under agitation (Fig. 2), the separation was better, according to the welldistinguished flavor of cultivars BRS 232 and BRS 267. At $20 \mathrm{~min}$ agitation (T20), samples were stabilized showing the tendency already observed. The first principal component (PC1) explained $95.99 \%$ of the total variance, while the second principal component (PC2) explained $2.12 \%$ (Fig. 3).

Since for all the three extraction time, the grain type cultivar BRS 232, which presented bad flavor, was always in a distinguished position when compared with the other better flavor cultivars BRS 257 and BRS 267, it was assumed that electronic tongue system analyses could be 
effective in determining the flavor of a large number of samples. Results indicated that when the objective was to reduce the time for flavor extraction, 1 to $10 \mathrm{~min}$ agitation for flavor extraction were reasonable times for sample preparation. For this work, 1 min was selected as the extraction time for sample preparation where total variance for PC1 and PC2 was 95.17\% (Fig. 1). However, for future works, it would be better to test $5 \mathrm{~min}$, which could improve flavor extraction without interfering in time consuming analyses by ET system.

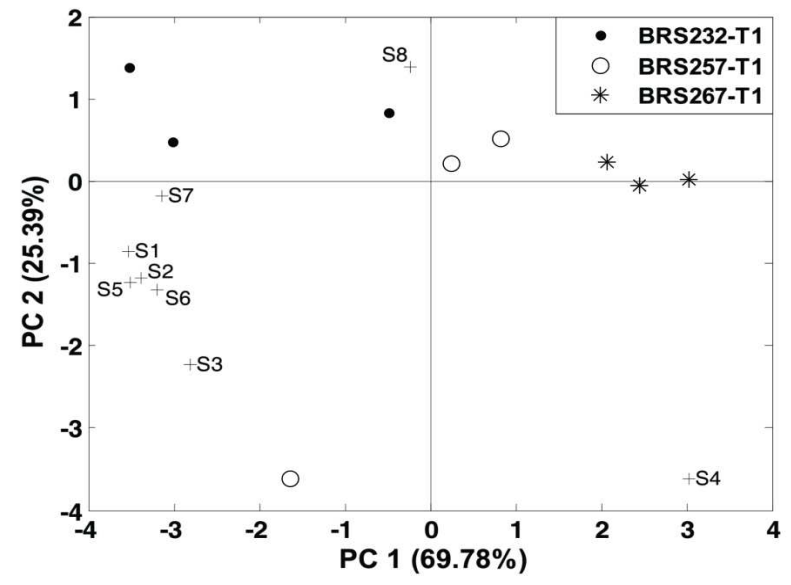

Figure 1 - Projection of flavor of soybean cultivars BRS 232, BRS 257 and BRS 267, on the factorial plane (PC1 and PC2) of Principal Component Analysis (PCA), analyzed by the electronic tongue system submitted to $01 \mathrm{~min}$ of magnetically agitation for flavor extraction = $\mathrm{T} 1$ (3 replications).S1 to $\mathrm{S} 8$ are the electronic sensors.

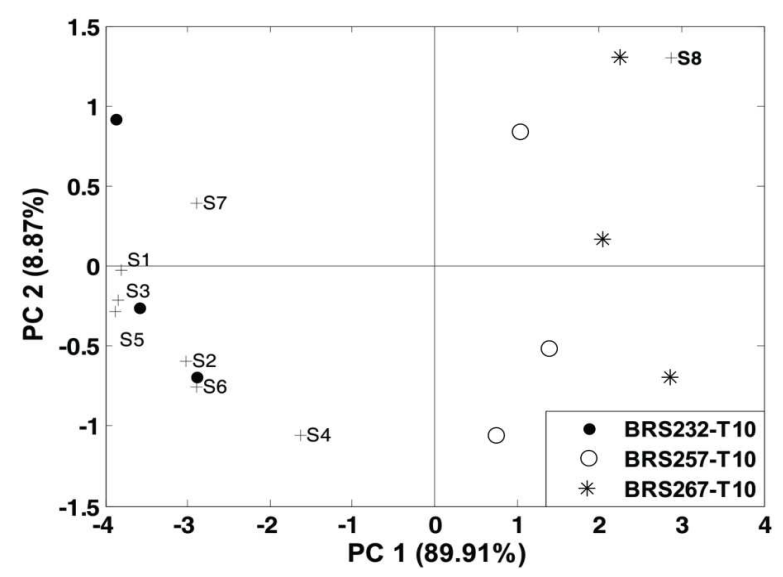

Figure 2 - Projection of flavor of soybean cultivars BRS 232, BRS 257 and BRS 267, on the factorial plane (PC1 and PC2) of Principal Component Analysis (PCA), analyzed by the electronic tongue system submitted to $10 \mathrm{~min}$ of magnetically agitation for flavor extraction $=$ $\mathrm{T} 10$ (3 replications). $\mathrm{S} 1$ to $\mathrm{S} 8$ are the electronic sensors.

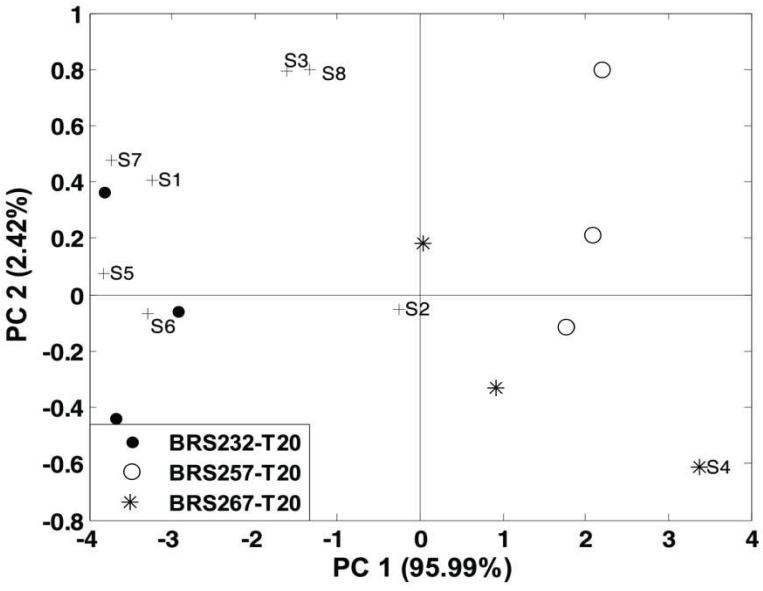

Figure 3 - Projection of flavor of soybean cultivars BRS 232, BRS 257 and BRS 267, on the factorial plane (PC1 and PC2) of Principal Component Analysis (PCA), analyzed by the electronic tongue system submitted to $20 \mathrm{~min}$ of magnetically agitation for flavor extraction $=$ $\mathrm{T} 20$ (3 replications). $\mathrm{S} 1$ to $\mathrm{S} 8$ are the electronic sensors.

\section{Experiment 2 - Flavor analysis of the breeding lines.}

After defining the time for sample preparation, flavor of different breeding lines was evaluated. The electronic tongue system was able to distinguish soybean flavor differences. Silva et al. (2012) reported the efficiency of the electronic tongue to distinguish the flavor attributes of five different soybean cultivars. Chemical constituents and sensory attributes had a good correlation with data of the electronic tongue, which was similar to the human trained panel. These authors also showed that cultivars BRS 267 and BRS 213 (null lipoxygenase), probably due to greater intensity of the flavor attributes such as sweetness aroma, sweet, and umami, were located in the same side of the PCA graphic, and similar results were observed for BRS 267 and BRS 257 in this experiment.

According to the soybean breeding program for special attributes related to food quality the following characters were presented in the 25 genotypes evaluated: better flavor due vegetable types and null lipoxigenase, high protein content, reduced trypsin inhibitor, reduced phytate, black seed coat, large and small seed size (Table 1). In the spatial distribution of the PCA graphic, all the lines close to each other were similar in flavor, while the distant lines were different (Fig. 4). Therefore, by observing the characters evolved in the crosses representing by the genetic 
background of these lines, it was possible to identify flavor similarities or differences (Table $1)$.

Genotypes that present vegetable types in their genealogy, which in general present sweet or umami flavor, as observed by Silva et al. (2009), are projected in the right side of the graphic, forming two different groups, which can be related to the parental differences. Vegetable types are large seed size soybeans that present milder flavor and can be consumed as edamame (traditional Japanese food made of cooked green pods). The superior flavor of these genotypes is due to higher content of sucrose, glutamic acid and alanine (Masuda 1991). The same author also reported the content of starch in these soybeans, which improved the texture of the product. All these components of vegetable types confer a genuine flavor to soybean that is different from flavor of null lipoxygenase character. This difference could be observed in the PCA projection graphic, where genotypes with absence of lipoxygenases were located at left side, in a different position of the vegetable ones.

The absence of enzymes lipoxygenases is the characteristic that also improves the flavor of soybean by preventing the formation of n-hexanal, the compound responsible for the beany flavor (Wilson 1996). Removal of lipoxygenases produced a desirable "bland" soybean, which was classified as neutral flavor by Silva et al. (2012). This neutral flavor is the different flavor of the vegetable types. Electronic tongue seemed to be very perceptive, because among the tested lines, two groups originated from the same crosses, presented their lines very close (21A and $21 \mathrm{~B}$, and 24A, 24B and 25) (Fig. 4). This data showed consistency and efficiency of the electronic tongue system in detecting the flavor differences and similarities. Oliveira et al. (2010) analyzed soybean genotypes for sugar, oligosaccharides and starch content, and reported that F83-5782, Late Giant, F83-8119, Tamahomare e BRS 267 could be genetic sources to increase the starch content. They observed that BRS 267, Tamahomare and Late Giant also presented high content of sacarose. Starch and sacarose can have positive influence on flavor characteristics by changing the texture and sweetness. Therefore, an interesting observation in this work was that the lines of the two "superior flavor" groups had those genetic sources in the genealogy.

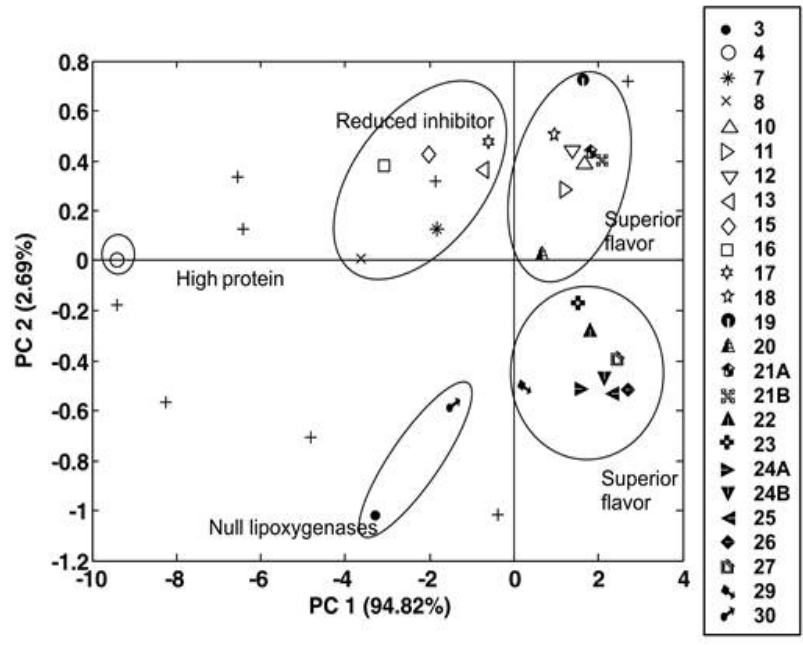

Figure 4 - Projection of mean flavor of different breeding lines on the factorial plane (PC1 and PC2) of Principal Component Analysis (PCA) analyzed by the electronic tongue system in three replicates. S1 to S8 are the electronic sensors.

The genotypes that were not developed to improve the flavor, but just evolved characters for high protein content and reduced anti nutritional factors (trypsin inhibitor and phytate), were clearly separated from the genotypes with better flavor (Fig. 4). Therefore, to attend market preferences and to increase the acceptability of soybean foods, a breeding program has been developed at Embrapa to obtain soybean cultivars with special attributes such as high content of protein $(42-$ $45 \%)$, large and small seed size, black seed coat, yellow hilum and mainly better flavor (CarrãoPanizzi et al. 2009). Some cultivars have been released and lines are being tested in final essay evaluations. Flavor is a limiting factor for soybean acceptability, which means that flavor evaluation by using the electronic tongue system will be a very useful tool. This is particularly important when a large number of lines should be evaluated in different stages of the breeding program.

\section{CONCLUSIONS}

- The electronic tongue system could be efficient to analyze a large number of samples, making possible flavor evaluation of breeding lines.

- An easy method for flavor extraction is important to speed up the analyzes by the electronic tongue system. 


\section{ACKNOWLEGMENTS}

We are grateful to the National Brazilian Research Council for the financial resources to develop this work and to the cooperation of Embrapa Agro Instrumentation and Polytechnic School of University of São Paulo at the project - MP -1 Nanotechnology Applied to Agribusiness - Sensors and Biosensors.

\section{REFERENCES}

Andersson K. Functionally test with the electronic tongue. [MSc. Thesis], Orebro, Sweden, Orebro University, 2003.

Braga GS, Paterno LG, Lima JPH, Fonseca FJ, Andrade AMde. Influence of the deposition parameters on the morphology and electrical conductivity of PANI/PSS self-assembled films. Mat Sci Eng. 2008; 28: 555-562.

Borato CE. Estudos de filmes poliméricos ultrafinos de polianilinas para aplicação em sensores de gases. [Dissertação Mestrado]. São Paulo: Escola Politécnica Universidade de São Paulo; 2002.

Carrão-Panizzi MC. Melhoramento genético para obtenção de cultivares de soja mais adequadas ao consumo humano. Rev Bra Nutr Clín. 2000; 15: 330340.

Carrão-Panizzi MC, Pípolo AE, Mandarino JMG, Arantes NE, Garcia A, Benassi VdeT, et al. Breeding specialty soybean cultivars for processing and valueadded utilization at Embrapa in Brazil. In: VIII World Soybean Research Conference: Proceedings; 2009, Beijing, China:Chinese Academy of Agricultural Sciences: Institute of Crop Science, 1 CD-ROM.

Decher G. Fuzzy Nanoassemblies: Toward Layered Polymeric Multicomposites, Science. 1997; 277: 1232-1237.

Dyminski SD, Paterno LG, Takeda HH, Bolini HM, Mattoso, LHC, Candido, LMB. Correlation between human panel and electronic tongue responses on the analysis of commercial sweeteners. Sensor Letters. 2006; 4: 1-6.

Furuta S, Nishiba V, Hajika M, Igita K, Suda I. Detba value and hexanal production with the combination of unsaturated fatty acids and extracts prepared from soybeans seeds lacking two or three lipoxygenase isozymes. J Agric Food Chem. 1996; 44: 236-239.

Gregorut C. Avaliação do desempenho de uma língua eletrônica na identificação de cultivares de soja. [MSc. Thesis], São Paulo, Escola Politécnica da Universidade de São Paulo, 2010.
Kataoka M, Miyanaga Y, Tsuji E, Uchida T. Evaluation of bottle nutritive drinks using a taste sensor. Int J Pharmac. 2004; 279:107-114.

Legin A, Rudnitskaya A, Seleznev B, Vlasov YU. Recognition of liquid and flesh food using an electronic tongue. Int J Food Sci Tech. 2002; 37: 375-385.

Masuda R. Quality Requirement and Improvement of Vegetable Soybean. In: Shanmungasundaram S (ed) the Workshop Vegetable Soybean Research Needs for Production and Quality Improvement: Proceedings: 1991

Kenting, Taiwan: Vegetable Research and Development Center, 1991. p. 92-102.

Mattoso LHC, Taylor DM, Bone S, Mello SV, Gallardo AM, Riul A. An electronic tongue using polypyrrole and polyaniline. Synth Metals. 2002; 132: 109-116.

Meilgaard M, Civille GV, Carr BT. Sensory Evolution Techniques. London: CRC Press Inc; 1999.

Oliveira MA, Carrão-Panizzi MC, Mandarino JMG, Leite RS, Campos Filho PJde, Vicentini MB. Quantificação dos teores de açúcares, oligossacarídeos e amido em genótipos/cultivares de soja (Glycine $\max$ (L.) Merrill) especiais utilizados para alimentação humana. Braz J Food Technol. 2010; 13(1): 23-29.

Paterno LG, Mattoso LHC, Oliveira JrON. Filmes poliméricos ultrafinos produzidos pela técnica de automontagem: preparação, propriedades e aplicações. Quím Nova. 2001; 24(2):228-235.

Paterno LG, Mattoso LHC. Effects of $\mathrm{pH}$ on the preparation of self-assembled films of poly (omethoxyaniline) and sulfonated lignin. Polym. 2001; 42:5239-5245.

Silva JB, Carrão-Panizzi MC, Prudêncio SH. Chemical and physical composition of grain type and food type soybean for food processing. Pesq Agropec Bra.s 2009; 44: 777-784.

Silva J, Prudêncio S, Carrão-Panizzi M, Gregorut C, Fonseca F, Mattoso L. Study of the flavour of soybean cultivars by sensory analysis and electronic tongue. Int J Food Sci Tech. 2012; 47: 1630-1638.

Stone H, Sidel J. L. Sensory Evaluation Practices Food Science and Technology, International Series. Netherlands: Elsevier Academic Press; 2004.

Wilson L. Comparison of lipoxygenase-null and lipoxygenase-containing soybeans for foods. In: Piazza GJ (ed.)

Lipoxygenase and lipoxygenase pathway enzymes. Champaign, USA: AOCS Press; 1996.

Received: July 11, 2013; Accepted: February 18, 2014. 